\title{
Geothermal study to explain man-made permafrost in tailings with raised surface
}

\author{
Roger Knutsson $^{1} \mathbb{D} \cdot$ Peter Viklander $^{1} \cdot$ Sven Knutsson ${ }^{1} \cdot$ Jan Laue $^{1}$
}

Received: 5 September 2017 / Accepted: 31 March 2018

(c) The Author(s) 2018

\begin{abstract}
Deposition of mine tailings in a cold climate requires precautions as temporary sub-zero temperatures can imply considerable consequences to the storage due to creation of permafrost. The risk of creating man-made permafrost lenses due to tailings deposition exists even in regions with no natural permafrost, as material being frozen during winter might not fully thaw by the following summer. When such frozen layers thaw during later longer warmer periods, excess pore water pressure and large settlements might develop. Such implications close to the dam structure have to be avoided and therefore the risk of generating permafrost should be reduced. This paper describes a geothermal model for one-dimensional heat conduction analysis. The model is able to simulate the temperature profile in tailings where the surface elevation is constantly increased due to deposition. At the tailings surface, the boundary condition is the air temperature changing over time during the year. Air temperatures, tailings deposition schedule and tailings properties are given as input to the model and can easily be changed and applied to specific facilities. The model can be used for tailings facilities in cold regions, where the effects of tailings deposition on the temperature regime are of interest. Findings can improve tailings management by explaining man-made permafrost generation. The model can also aid in setting up appropriate deposition schedules and to prevent generation of permafrost layers.
\end{abstract}

Keywords Tailings $\cdot$ Geothermal model $\cdot$ Freezing $\cdot$ Thawing $\cdot$ Tailings deposition $\cdot$ Permafrost

\section{Introduction}

Tailings management in a cold climate requires certain precautions. Freezing of pipes, malfunctioning instrumentation or heavy snowfall can all imply disturbances in tailings operations. Tailings deposition must be conducted in a way that freezing/thawing does not add to additional risks in tailings dam performance.

At sub-zero temperatures heat is transmitted out of the tailings and a frost front penetrates downwards. In summer heat is added to the tailings from the air and the frozen tailings thaw. In areas without natural permafrost the added heat during summer is greater than what is released during winter. Thus, the thaw depth reaches the maximum frost depth formed during winter. Permafrost is defined as a state

Roger Knutsson

roger.knutsson@ltu.se

1 Department of Civil, Environmental and Natural Resources Engineering, Luleå University of Technology, 97187 Luleå, Sweden where soil remains frozen over at least two consecutive winters, including the intermediate summer (Andersland and Ladanyi 2004).

Tailings storage facilities (TSFs) are continuously growing structures as their heights increase as deposition prevails. Therefore, the energy balance is different compared to that of static structures with constant geometric boundary conditions. During deposition, the energy that is withdrawn from a certain depth during winter might not be re-entered to the same depth during summer due to the increased height of the structure, see Fig. 1. Part of the tailings that freeze during winter might therefore remain frozen after the following summer, and thus permafrost is generated. Indications of such man-made permafrost have also been observed in facilities in Sweden, even in regions without natural permafrost. A photo from an excavated trial pit, indicating such a frozen layer, is presented in Fig. 2. The photo was taken during late summer whilst thaw was taking place from above, with approximately $1 \mathrm{~m}$ of frozen material remaining.

In cases where embedded frozen layers thaw, excess pore water pressures (Morgenstern and Nixon 1971), large 


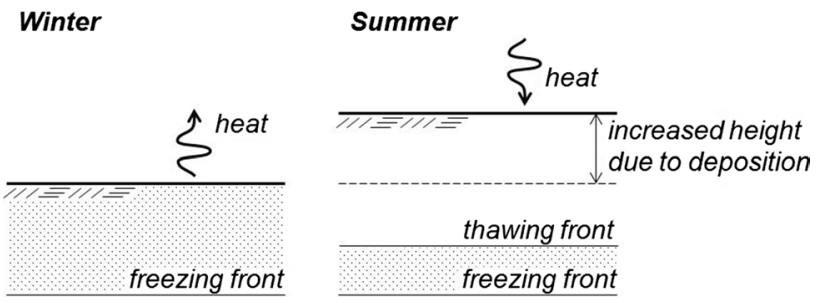

Fig. 1 Heat withdrawn (winter) and re-entered (summer) in tailings with increased height

settlements (Wang et al. 2014) and thaw stability issues (McRoberts and Morgenstern 1974) might occur. These can have significant influence on the tailings dam safety (Knutsson et al. 2016; Korshunov et al. 2016), and therefore the generation of man-made permafrost in non-permafrost regions should be prevented.

Guidelines on how to optimize tailings deposition with respect to sedimentation, consolidation and desiccation (Qiu and Sego 2006) are available for tailings management. With careful operation procedures in terms of tailings deposition, it is possible to control (within limits) the tailings density, compressibility, permeability and shear strength in different zones of a tailings facility (Blight 2010). However, studies on the freezing/thawing aspects associated with tailings deposition are very limited in literature. Nixon and Holl (1998) modelled the geothermal regime in tailings with deposition and concurrent freezing and they showed that generation of layered permafrost in tailings impoundments might take place. Caldwell et al. (2014) adjusted the tailings deposition to seasonal aspects to gain property enhancements in the tailings due to freezing/thawing, but where the thermal regime was disregarded. No studies or guidelines have been found on how to manage tailings deposition in a cold climate or to prevent permafrost generation. Thus, there is a need for a methodology to model the geothermal regime in tailings, taking into account site specific conditions such as deposition rate, tailings properties and climatic conditions. This paper presents the set-up of such a simplified model. The model can be used for explaining the generation of manmade permafrost. It can also be used by engineers in setting up deposition schedules, winter planning and related topics for tailings management in cold regions.

\section{Method}

A model has been generated where the finite difference method was used for one-dimensional heat conduction analysis. The model was created in MATLAB (MathWorks Inc. 2016). For the analysis, moving boundaries (space vs. time) were included by increased layer thickness (raised tailings surface) and moving freeze/thaw fronts. At the tailings surface (upper limit) a periodical boundary condition (temperature change over time) was applied, and in the bottom a fixed boundary (temperature) was applied. Site specific data representing any tailings facility of interest was read as input to the model. Also, ratios between air and ground surface temperatures ( $n$-factors) were given as input. A schematic flowchart of the model is presented in Fig. 3, which will be
Fig. 2 Photo from a TSF in northern Sweden, indicating a permafrost layer

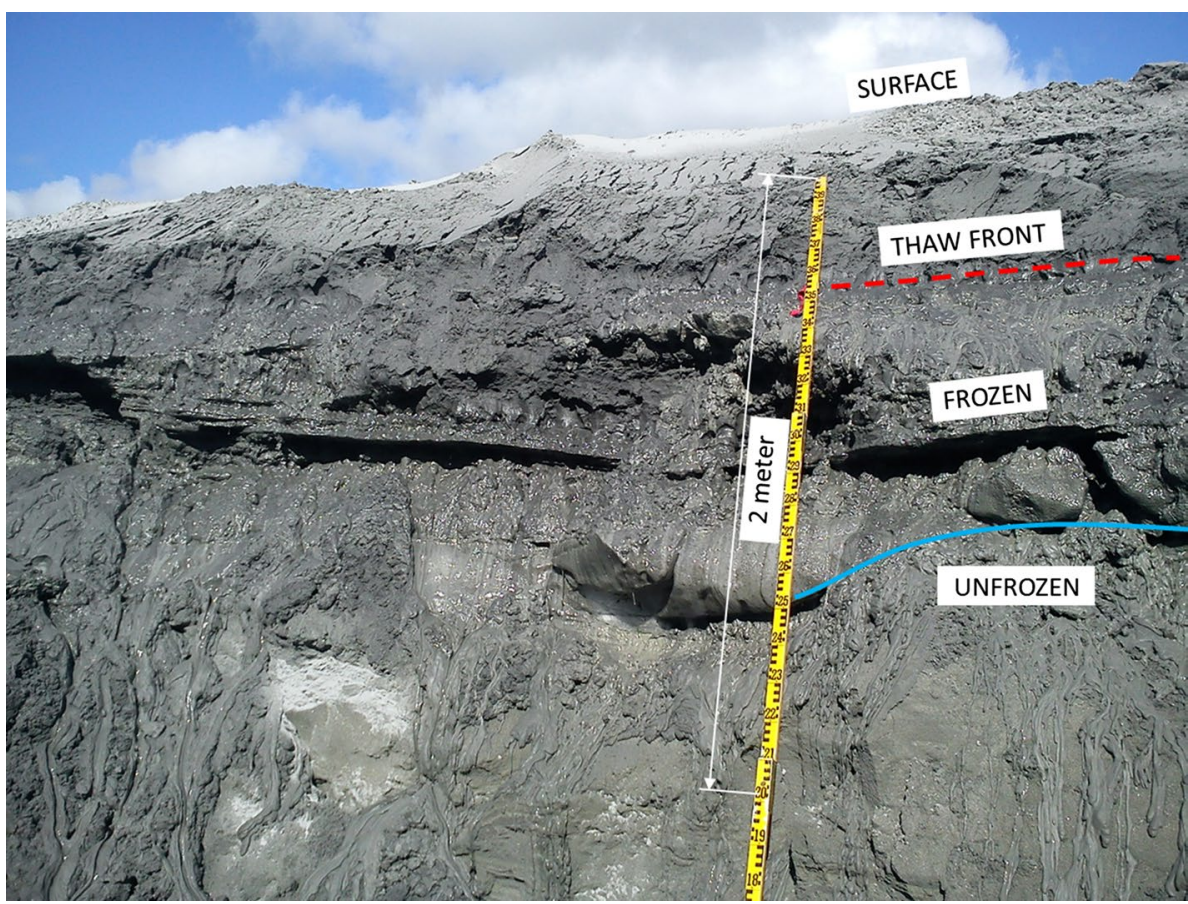


Fig. 3 Schematic flowchart of the model

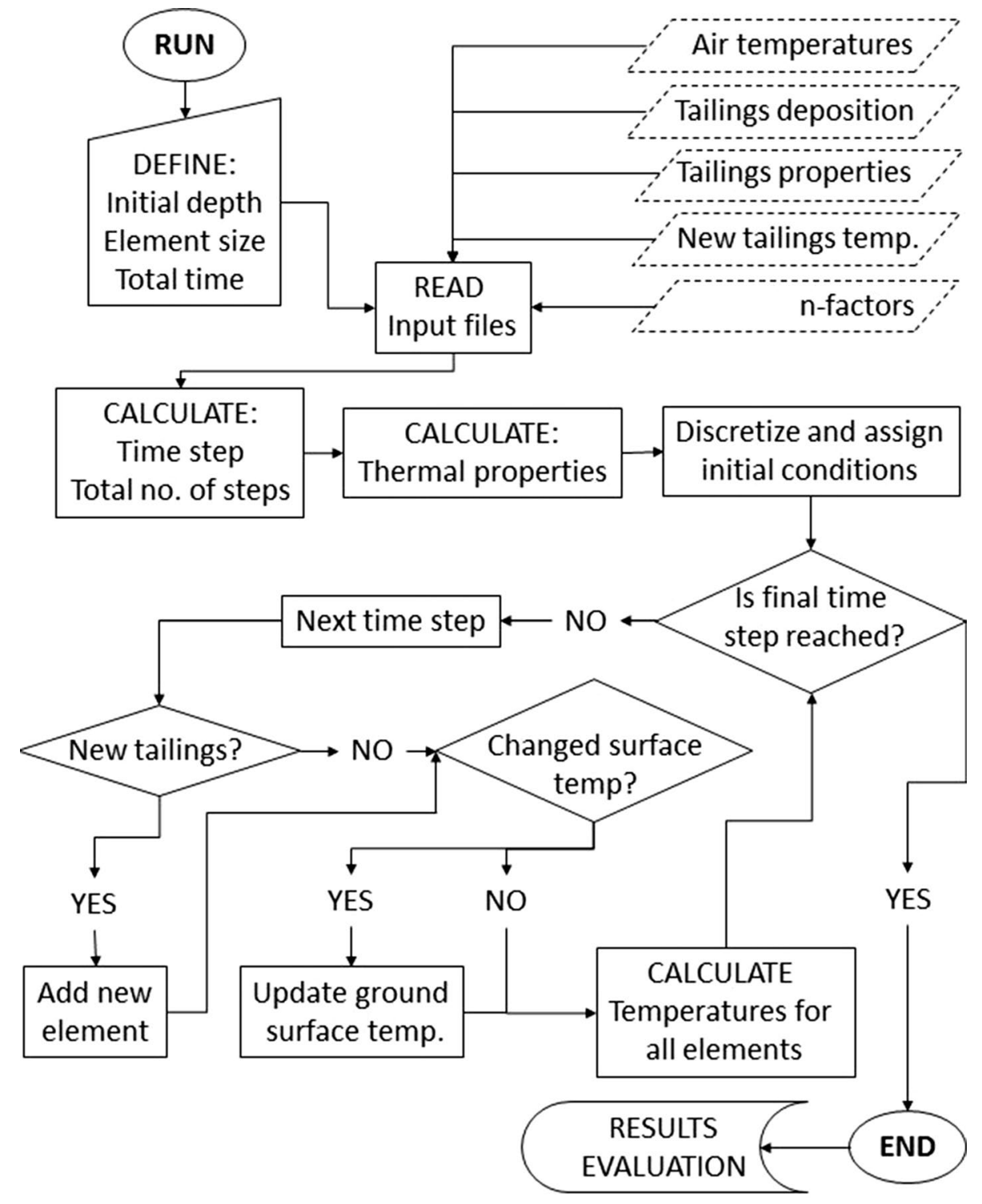

further explained in the following sections. In this paper simulation examples were performed with temperature data representing a mining district in northern Sweden.

The equation for one-dimensional heat conduction including phase change is given in Eq. (1).

$C \frac{\partial T}{\partial t} \pm \frac{L^{\prime}}{\partial t}-\frac{1}{\partial x}\left(k \frac{\partial T}{\partial x}\right)=0$

where $C$ volumetric heat capacity for the soil mixture $[\mathrm{J} /$ $\left.\left(\mathrm{m}^{3}{ }^{\circ} \mathrm{C}\right)\right], T$ temperature $\left({ }^{\circ} \mathrm{C}\right), t$ time $(\mathrm{s}), L^{\prime}$ volumetric latent heat $\left(\mathrm{J} / \mathrm{m}^{3}\right), x$ depth from the tailings surface $(\mathrm{m}), k$ thermal conductivity for the tailings mixture $\left[\mathrm{J} /\left(\mathrm{s} \mathrm{m}{ }^{\circ} \mathrm{C}\right)\right]$.

The first term in Eq. (1) corresponds to change in energy storage. The second term corresponds to the latent heat that is released ( -$)$ when freezing, or absorbed $(+)$ when thawing. The third term corresponds to net energy flow by conduction. The sum of these terms is zero, assuming no other ways of energy flow than conduction. Neither heat flow by radiation, nor by convection is taken into consideration in Eq. (1).

Equation (1) was solved numerically by a finite difference method. An explicit method was used (FTCS, forward-time central space method). The finite difference equation for heat conduction is presented in Eq. (2), after Ho et al. (1970).

$T_{j, t+1}=T_{j, t}+\frac{2 \mathrm{~d} t}{C_{j} \mathrm{~d} x^{2}}\left(\frac{\left(T_{j+1, t}-T_{j, t}\right)}{\left(\frac{k_{j+1}+k_{j}}{k_{j+1} k_{j}}\right)}-\frac{\left(T_{j, t}-T_{j-1, t}\right)}{\left(\frac{k_{j}+k_{j-1}}{k_{j} k_{j-1}}\right)}\right)$,

where $\mathrm{d} t$ time step (s), $\mathrm{d} x$ element size (m), Subscripts $j$ and $t$ denotes position and time, respectively.

The release/absorption of latent heat was not explicitly taken into consideration in Eq. (2). The phase change was 
controlled separately by setting the element temperature to $0{ }^{\circ} \mathrm{C}$ until the accumulated heat flow from/to the element exceeded the latent heat. The temperature was then again computed with Eq. (2). The fixed phase change temperature $\left(0{ }^{\circ} \mathrm{C}\right)$ is a known limitation in the model. For fine grained soils there can be unfrozen water in sub-zero temperatures and associated depression of the freezing temperature. Wen et al. (2012) found significant amounts of unfrozen water in a silty clay when subjected to sub-zero temperatures, and showed that unfrozen water and soil matric potential clearly influence moisture migration in freezing soil. A review on frost-heave research and ice-lens formation is presented by Peppin and Style (2013) who discussed models on how to explain moisture migration and frost heave. Ma et al. (2015) studied the effects of a non-linear relationship between unfrozen water and freezing temperatures. They discussed the phase change process, the mechanical equilibrium in the phase transition zone, and the applicability of the Clausius-Clapeyron equation in soil freezing. Despite the limitation regarding unfrozen water content and frost depression, the model proposed in this study is considered valid for tailings that normally consist of fractions as silty sand (Vick 1990). Sandy soils are generally insensitive to unfrozen water content in sub-zero temperatures and the freezing temperature depression is low (Andersland and Ladanyi 2004). Therefore, the model is considered applicable for tailings with grain sizes in the range of silty sand to sand.

The model was here set up to simulate $8 \mathrm{~m}$ of tailings (as initial depth). The element size ( $\mathrm{d} x$ ) was chosen as $0.05 \mathrm{~m}$ and the total simulation period was 5 years. At the tailings surface a periodical temperature condition was used, i.e., air temperatures with time. The ground surface temperature was calculated in a hypothetical element at the tailings surface using a constant temperature ratio between air and ground temperatures, the $n$-factor. Eventual snow cover on the surface was not incorporated in the model.

To get stable solutions, the maximum time step according to Eq. (3) was used, after Ho et al. (1970). Equation (3) corresponds to the stability limit in finite difference schemes; see, e.g., Kincaid and Cheney (2002), where the time step relates the increment to the physical properties of the layer (Ho et al. 1970). In general, the allowable time step decreases with reduced element size, or increased thermal conductivity.

$\mathrm{d} t \leq \frac{C_{j} \mathrm{~d} x^{2}}{2} \cdot\left(\frac{k_{j+1}+k_{j}+k_{j-1}+\frac{k_{j+1} k_{j-1}}{k_{j}}}{2 k_{j+1} k_{j-1}+k_{j} k_{j+1}+k_{j} k_{j-1}}\right)$

\section{Tailings properties}

Thermal properties needed for the tailings are thermal conductivity $(k)$, volumetric heat capacity $(C)$ and volumetric latent heat $\left(L^{\prime}\right)$. The parameters have been calculated based on methods given in Andersland and Ladanyi (2004) with the assumption that no unfrozen water was present in the frozen tailings. The thermal conductivity of the tailings was calculated with the model proposed by Johansen (1975). He expressed the unsaturated thermal conductivity in terms of the dry and saturated thermal conductivities of the soil. The thermal conductivity of dry soil is assumed to be a function of dry density. For saturated conditions, it is expressed as a geometric mean of thermal conductivity of the soil's solid and water components. The thermal conductivity of the solid component is mainly dependent on the quartz content of the solid grains. Johansen's model has been confirmed to accurately predict the thermal conductivity for a wide range of soils and saturation levels, both in frozen, and unfrozen states (Farouki 1986; Barry-Macaulay et al. 2015). It is therefore considered appropriate for estimating the thermal conductivity of the tailings. The specific gravity $\left(G_{\mathrm{S}}\right)$, quartz content in the grains $(q)$, dry density $\left(\rho_{\mathrm{d}}\right)$ and degree of water saturation $\left(S_{\mathrm{r}}\right)$ were read as input to the model and used for calculation of the thermal properties. The different thermal properties for unfrozen and frozen tailings, respectively, have been used. The calculated properties were assumed to be constant over time and depth.

\section{Tailings deposition}

Tailings deposition has been considered as a raised tailings surface with time. For time steps where tailings were deposited, a new element was added as the uppermost soil element in the model. Its location was between the element where the ground surface temperature was calculated and the previous soil element. This is illustrated in Fig. 4, in which the new inserted element is marked with "NEW".

The new element was given the same properties as the uppermost element in the previous time step. The temperature for the new element was read as input to the model, here set to $15^{\circ} \mathrm{C}$. The corresponding values at the end of the time step were calculated with Eq. (2). The value of $15{ }^{\circ} \mathrm{C}$ corresponds to the temperature of fresh tailings when deposited, assumed to be close to room temperature (i.e., temperature in the extraction plant). This temperature was set to be constant over the year, assuming no significant effect on the frost and thaw depths, which was shown by Nazarova et al. (2015). The temperature's impact on the results was also studied; see "Sensitivity analysis" section.

Model elements for three time steps are schematically illustrated in Fig. 4. Before any calculations were performed for a new time step, the boundary condition representing the ground surface temperature was updated. In addition, the $x$-coordinate which represents the depth from the ground surface was changed when a new element was added, see Fig. 4. 
Fig. 4 Changed element set-up due to tailings deposition. Dashed elements represent the elements where conversion is made from air temperature to ground surface temperature. Red elements ("NEW") are added due to tailings deposition

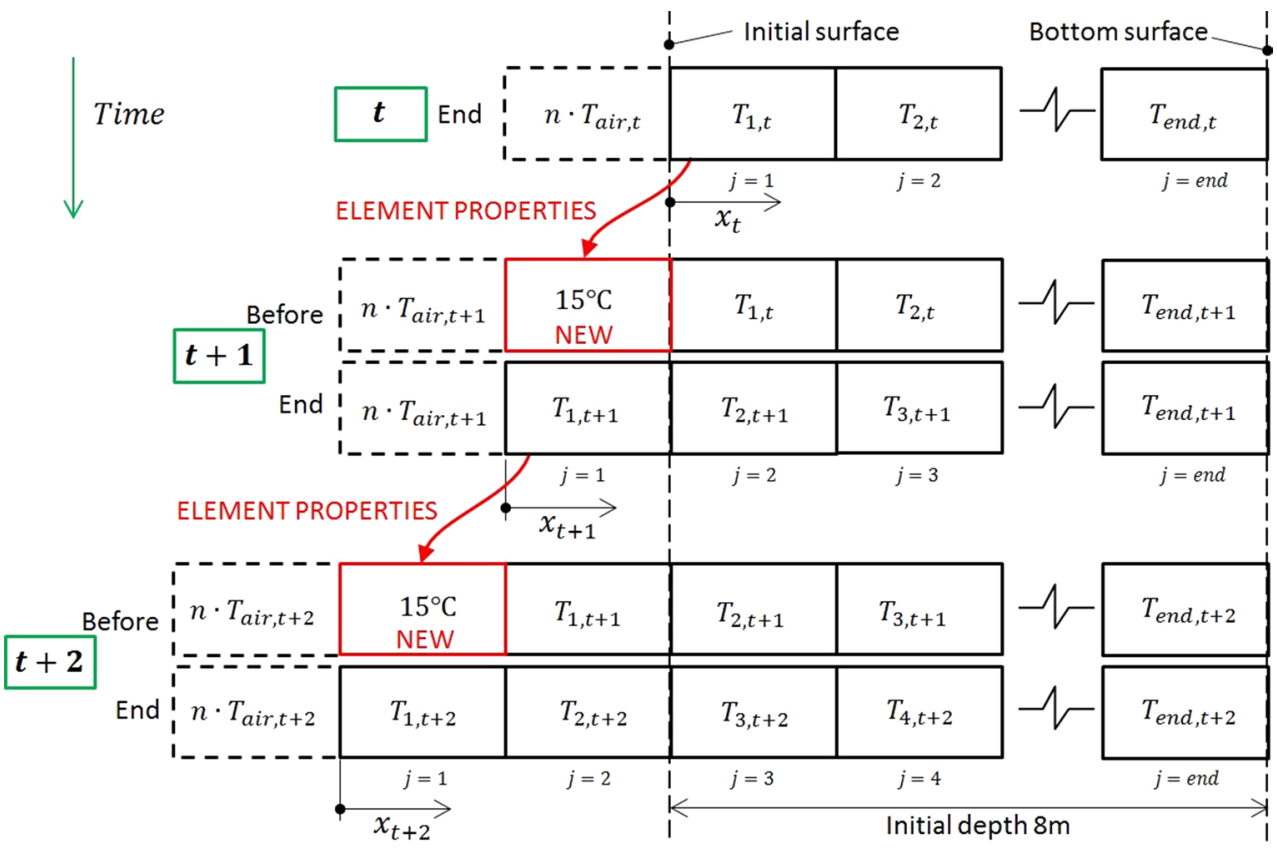

\section{Site specific input}

The model was set up with the possibility to read input data representing a certain tailings facility. The features used as input were (1) Air temperature, (2) Tailings deposition schedule, (3) Tailings properties, (4) New tailings temperature, and (5) $n$-factors.

Air temperature data was given in the format temperature with time, here read in excel format (.xls). As a simulation example, air temperatures representing a mining district in northern Sweden were used. The temperature scenario and the location are presented in Fig. 5. The temperature scenario is here representing a normal year, but could also have been imported as actual data directly from a weather station.

Tailings deposition was given in the format tailings height with time in excel format. Two examples were simulated. One example with no tailings deposition (constant tailings height with time) and the second having a constant height increase of $3 \mathrm{~m}$ per year, i.e., $15 \mathrm{~m}$ over the simulated time.
In the latter case, approximately every 6 days, the model has been raised with a new element.

The tailings properties used were specific gravity $\left(G_{\mathrm{S}}\right)$ 2.8 , quartz content $(q) 40 \%$, dry density $\left(\rho_{\mathrm{d}}\right) 1.5 \mathrm{t} / \mathrm{m}^{3}$ and degree of water saturation $\left(S_{\mathrm{r}}\right) 100 \%$. These values correspond to water content $(w) 30.9 \%$ and correspond to expected in-place properties of the deposited tailings (Vick 1990). The properties were used to calculate the thermal properties in the model, presented in Table 1.

The temperature of new tailings was set to the constant value of $15^{\circ} \mathrm{C}$.

The $n$-factors were chosen as 0.9 for sub-zero temperatures and 2.0 for temperatures above zero. These values were used to calculate the ground surface temperature from the air temperature (changing with time). No information in literature has been found on $n$-factors for tailings. Therefore, the values were chosen to represent sandy soil in open conditions and no vegetation (Andersland and Ladanyi 2004). A constant temperature of $0.1{ }^{\circ} \mathrm{C}$ was set at the $8 \mathrm{~m}$ depth
Fig. 5 Air temperature scenario representing a mining district in Northern Sweden (star)
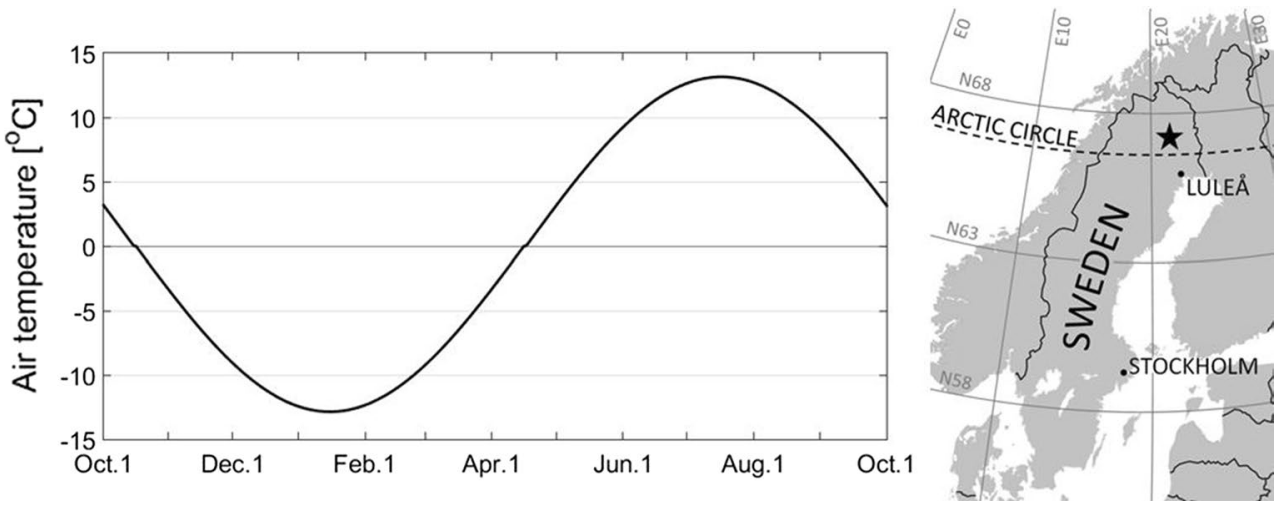
Table 1 Calculated thermal properties

\begin{tabular}{llll}
\hline & $\begin{array}{l}\text { Thermal conductivity } \\
k\left[\mathrm{~W} /\left(\mathrm{m}^{\circ} \mathrm{C}\right)\right]\end{array}$ & $\begin{array}{l}\text { Volumetric heat capac- } \\
\text { ity } C\left[\mathrm{~J} /\left(\mathrm{m}^{3}{ }^{\circ} \mathrm{C}\right)\right]\end{array}$ & Volumetric latent heat $L^{\prime}\left(\mathrm{J} / \mathrm{m}^{3}\right)$ \\
\hline Unfrozen tailings & 1.48 & $3.12 \times 10^{6}$ & $1.55 \times 10^{8}$ \\
Frozen tailings & 2.80 & $2.13 \times 10^{6}$ & \\
\hline
\end{tabular}

(maximum depth) as a fixed boundary condition. This temperature represents the average yearly temperature at the location.

For this study, there was no field data or other tailings temperatures available to use as the initial temperature condition. Instead, initial simulations were performed to estimate an appropriate temperature profile before the tailings deposition started. Ten years were simulated with changing temperatures at the surface (temperature scenario in Fig. 5), without any tailings deposition. Initial temperatures (start values) for this initial run were set to $0.1{ }^{\circ} \mathrm{C}$, which correspond to the average yearly temperature. The initial temperatures (start values) can be chosen to any value, but it was shown that after 3 years into the simulation their effects on the temperature profile had vanished. On October 1st, the temperature profile appeared the same every following year, i.e., the temperature profiles (on October 1st) between years 4 and 10 were identical. Therefore, the resulting temperature profile (year 4) was considered appropriate for the upcoming simulations with tailing deposition.

\section{Sensitivity analysis}

To illustrate the model parameters' impact on the simulations, a sensitivity analysis was conducted. The parameters used in the analysis were element size $(\mathrm{d} x)$, degree of water saturation $\left(S_{\mathrm{r}}\right)$, deposition rate (surface height increase per year), and temperature of new tailings added on top $\left(T_{\text {new }}\right)$. Each parameter was changed one at a time, keeping all other parameters at their original values.

The altered parameters are presented in Table 2. Original values correspond to the simulations explained in earlier sections. Lower and upper values were chosen to cover a range of model parameters. For the degree of water saturation, only lower values were possible since the original value was $100 \%$ (saturated).

The element size had a large impact on the computational effort. Not only was the number of elements increased when reducing the value, but the time step was also decreased, see Eq. (3). In this case, the lower value of element size $(0.01 \mathrm{~m})$ meant 125 times larger number of computations compared to the original value $(0.05 \mathrm{~m})$, i.e., 5 times the number of elements and 25 times the number of time steps. Similarly, the upper value $(0.1 \mathrm{~m})$ meant $12.5 \%$ of the number of computations compared to the original value $(0.05 \mathrm{~m})$, i.e., $50 \%$ of the number of elements and a $25 \%$ of the number of time steps.

The temperature of new tailings added on top was only studied for the case with tailings deposition ( $3 \mathrm{~m} / \mathrm{year})$.

\section{Limitations}

To the authors' knowledge, there is no model used today in tailings management where the depositional effects on the thermal regime are studied. Such a model should at least include continuous deposition or increased surface height with time and, therefore, it has to be noted that this study only takes the heat balance into account. Thus, no unfrozen water is considered in the frozen tailings, and correspondingly no cryogenic suction, moisture transfer, or ice lens formations are taken into consideration. Additionally, generation or dissipation of excess pore water pressure during thawing has been disregarded. Therefore, neither frost heaving, nor thaw consolidation settlements are modelled. Such frost actions will further change the thermal properties and balance.

Despite disregarding the hydro-mechanical aspects, insulating effects due to tailings deposition are covered. The simulations conducted here can explain the principle of generating man-made permafrost. Additionally, the model can help in setting up appropriate deposition schedules, to prevent permafrost generation.

Although no moisture transfer is included in the model, the effect of the water content on the thermal regime (by affecting the thermal properties) was studied in the sensitivity study. Its effect was shown to have less impact on the
Table 2 Parameters used in the sensitivity analysis

\begin{tabular}{llll}
\hline & Original value & Lower value & Upper value \\
\hline Element size, $\mathrm{d} x(\mathrm{~m})$ & 0.05 & 0.01 & 0.1 \\
Degree of water saturation, $S_{\mathrm{r}}(\%)$ & 100 & 66 & - \\
Deposition rate (m/year) & 3 & 1.5 & 6 \\
Temperature new tailings, $T_{\text {new }}\left({ }^{\circ} \mathrm{C}\right)$ & 15 & 10 & 20 \\
\hline
\end{tabular}


results compared to the depositional aspects. This further motivates the need to include surface height increase in geothermal modelling.

\section{Results}

\section{Temperature profile}

The calculation starts in October. The temperature profiles for the case with no tailings deposition are presented in Fig. 6. Three profiles covering the first year of the simulation are presented, i.e., representing February 1st, June 1st and October 1st (following year), respectively. The constant tailings surface corresponds to elevation 0. Results in Fig. 6 indicate that the frost penetration has reached $1.50 \mathrm{~m}$ in February 1 st. In June the freezing front has penetrated to $1.95 \mathrm{~m}$ below tailings surface, but at the same time the thaw depth has reached $0.85 \mathrm{~m}$, resulting in a $1.10 \mathrm{~m}$ thick frozen layer. In October (following year) no frozen tailings were present, i.e., all frozen materials were thawed. As the unfrozen tailings (at large depth) had a constant temperature of $+0.1{ }^{\circ} \mathrm{C}$ it is difficult to show the freezing front for the June-profile graphically. Locations of freezing and thawing fronts are further presented in the "Zero-isotherm" section.
Temperature profiles for the simulation with tailings deposition are presented in Fig. 7. The new elevation of the tailings surface was $1 \mathrm{~m}$ in February, $2 \mathrm{~m}$ in June and $3 \mathrm{~m}$ in October. The heat entering the tailings during summer was, therefore, entering the profile at a higher elevation than from where it was withdrawn. The increased tailings surface elevation was correspondingly resulting in thicker layers of frozen tailings compared to the results presented in Fig. 6. For October 1st there was $1.05 \mathrm{~m}$ of frozen tailings remaining in the profile, which is not present in Fig. 6 when the tailings were not raised.

\section{Zero-isotherm}

The moving freezing and thawing fronts with time are presented as the zero-isotherm(-s) in Figs. 8 and 9. The simulation with no tailings deposition (constant height) is presented in Fig. 8 and the case with tailings deposition ( $3 \mathrm{~m} /$ year) is presented in Fig. 9. Shaded areas in the figures represent frozen tailings.

For the case with no tailings deposition, all frozen tailings were thawed during the summer (as indicated in Fig. 6). The maximum frost depth reached in April was $1.95 \mathrm{~m}$. For the case with tailings deposition, embedded layers of frozen tailings were generated $(1.05 \mathrm{~m}$ in thickness). These layers remain frozen in the following seasons and are therefore regarded as permafrost.
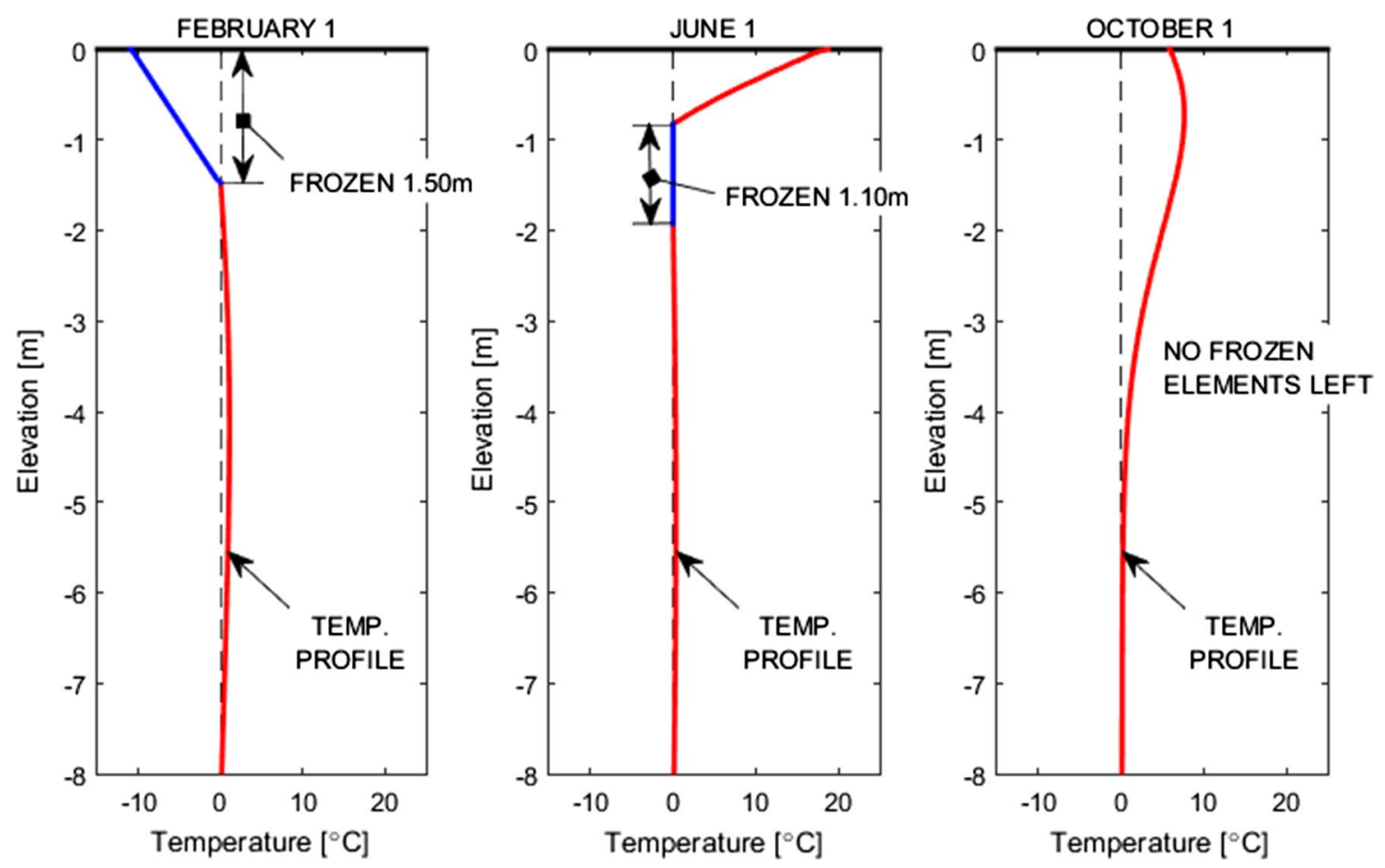

Fig. 6 Temperature profiles-no tailings deposition 

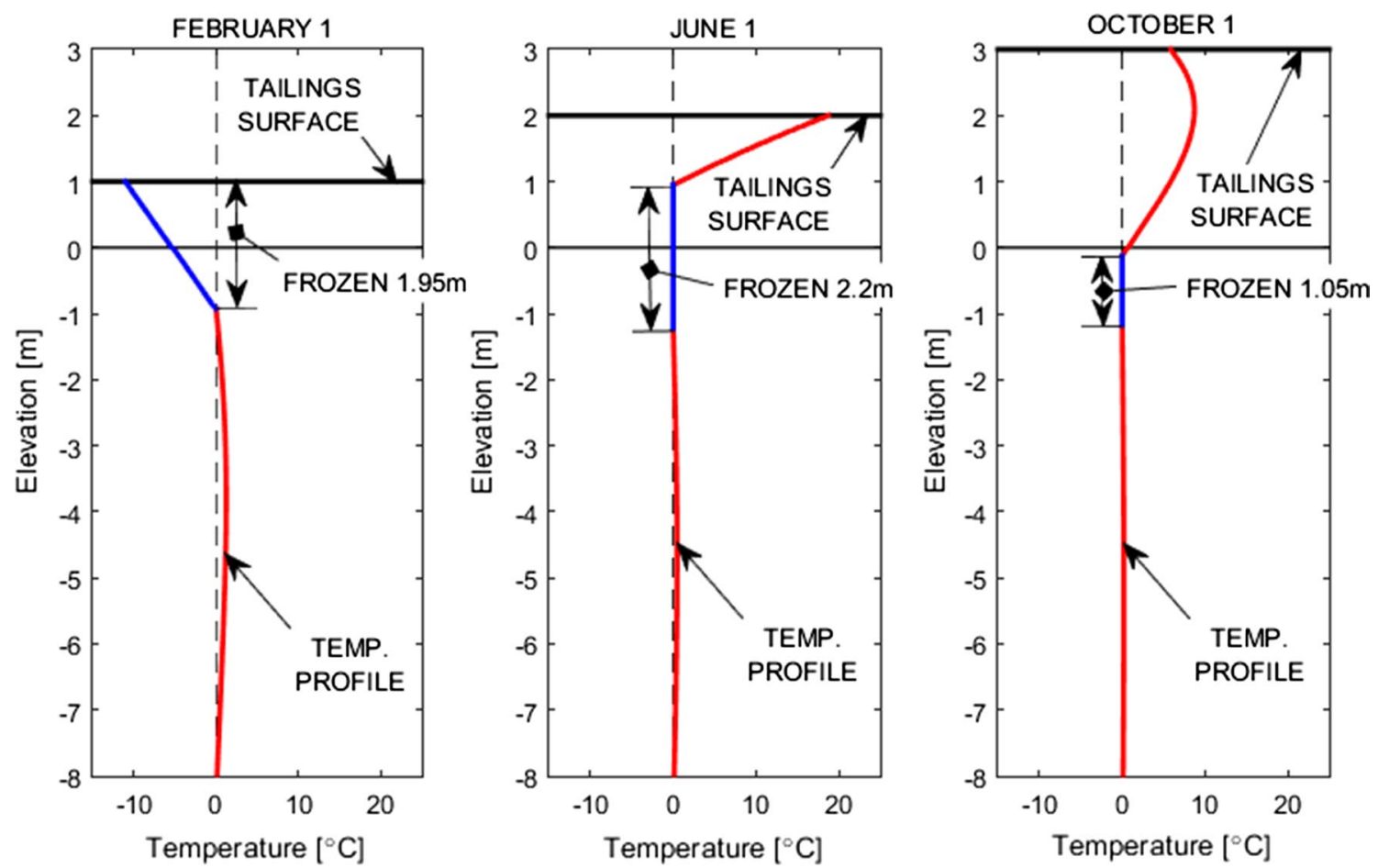

Fig. 7 Temperature profiles with tailings deposition ( 3 m/year)
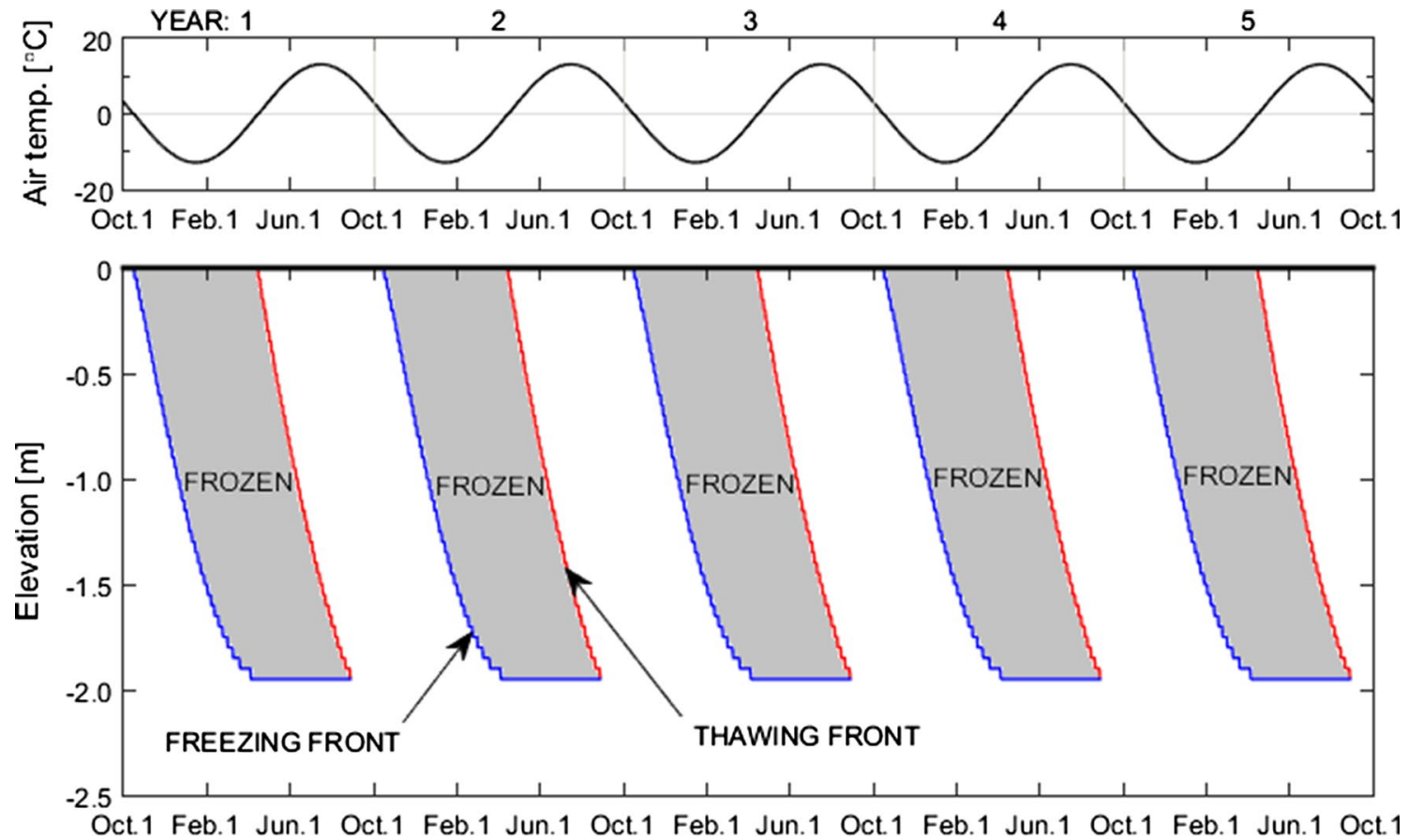

Fig. 8 Zero-isotherm for the simulation with no tailings deposition

\section{Sensitivity analysis}

In Fig. 10 the effect of element size $(\mathrm{d} x)$ is presented, where the upper row ( $a$ and $b$ ) correspond to the case without and the lower row (c and d) to the case with tailings deposition. The element size had a minor effect on the frost and thaw penetration independent of whether it was coarser or finer size. However, the "resolution" is the obvious difference 

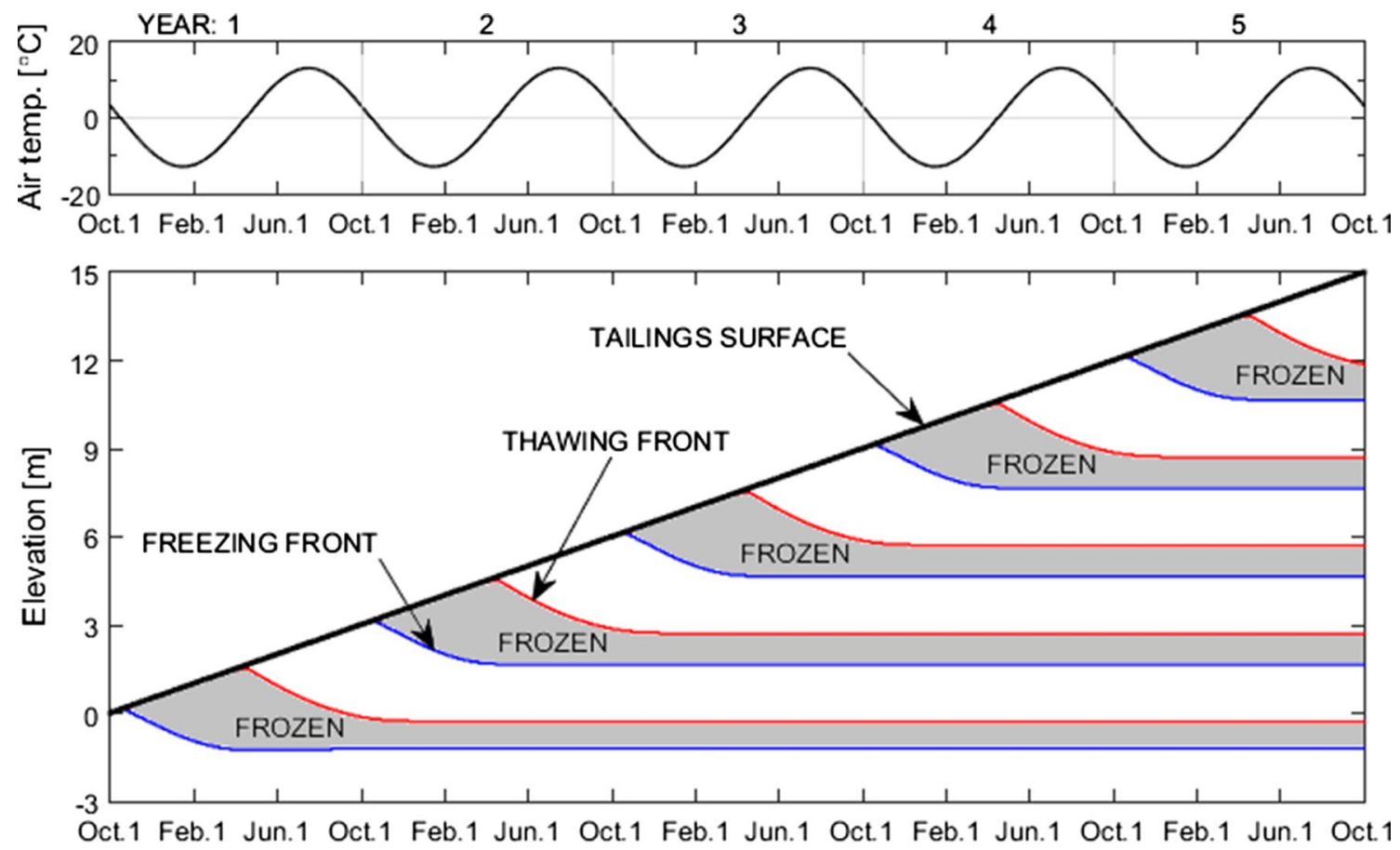

Fig. 9 Zero-isotherm for the simulation with tailings deposition $(3 \mathrm{~m} /$ year $)$
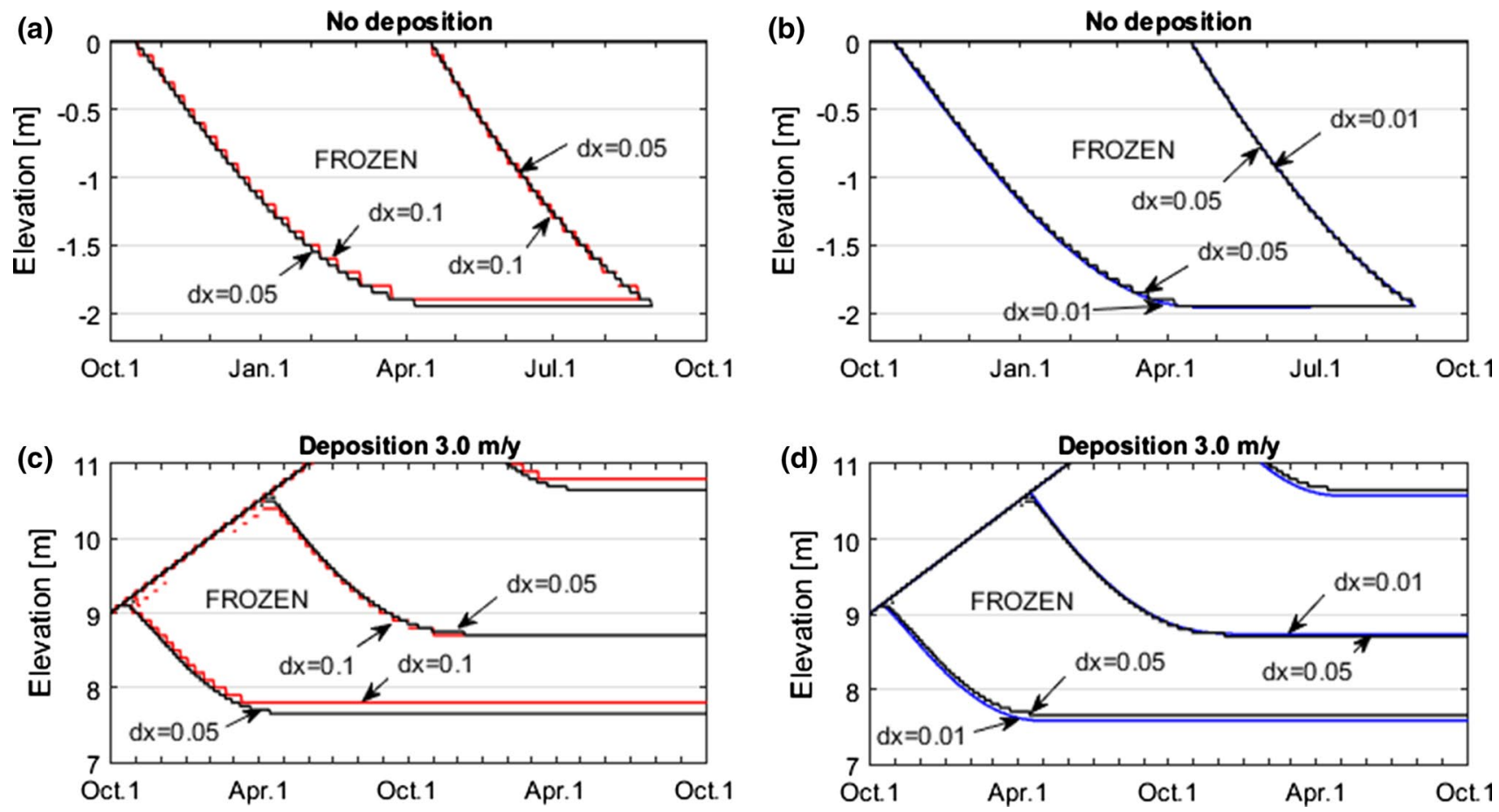

Fig. 10 Impact of element size. Black curves represent original values, i.e., $\mathrm{d} x=0.05 \mathrm{~m}$. Red curves $\mathrm{d} x=0.1 \mathrm{~m}$ (a, c) and blue curves $\mathrm{d} x=0.01 \mathrm{~m}(\mathbf{b}, \mathbf{d})$ 
between the results. The finer elements resulted in higher resolution in the frost/thaw depth penetration, with less "stairway steps" in the curves.

In Fig. 11 the effects of lower degree of water saturation $\left(S_{\mathrm{r}}\right)$ and deposition rates are presented. Figure 11a present zero-isotherms without deposition and Fig. 11b-d correspond to deposition rates $1.5,3.0$ and $6.0 \mathrm{~m} /$ year, respectively. Less water $\left(S_{\mathrm{r}}=66 \%\right)$ resulted in thinner layers of permafrost than was seen for saturated conditions. In general, the lower degree of saturation had a very low influence on the frost penetration, up to $0.05 \mathrm{~m}$ larger frost depths (i.e., one element), whereas larger differences were seen on the thaw penetration, up to $0.30 \mathrm{~m}$ larger thaw depths. Less water is expected to increase frost and thaw depths, but its larger influence on the thaw depth than on the frost depth explains the difference in permafrost thickness. Similar differences were seen for all cases with tailings deposition, irrespective of the deposition rate. But the largest impact on the permafrost generation was clearly due to the tailings deposition. Even for the low deposition rate of $1.5 \mathrm{~m} /$ year, permafrost was observed for both water contents studied. The permafrost thickness was also increased with increased deposition rate. The generation of permafrost is therefore considered to be more sensitive to tailings deposition than to possible changes in water content.

The temperature of the new tailings ( $\left.T_{\text {new }}\right)$ added on top was found to have very low influence on the frost and
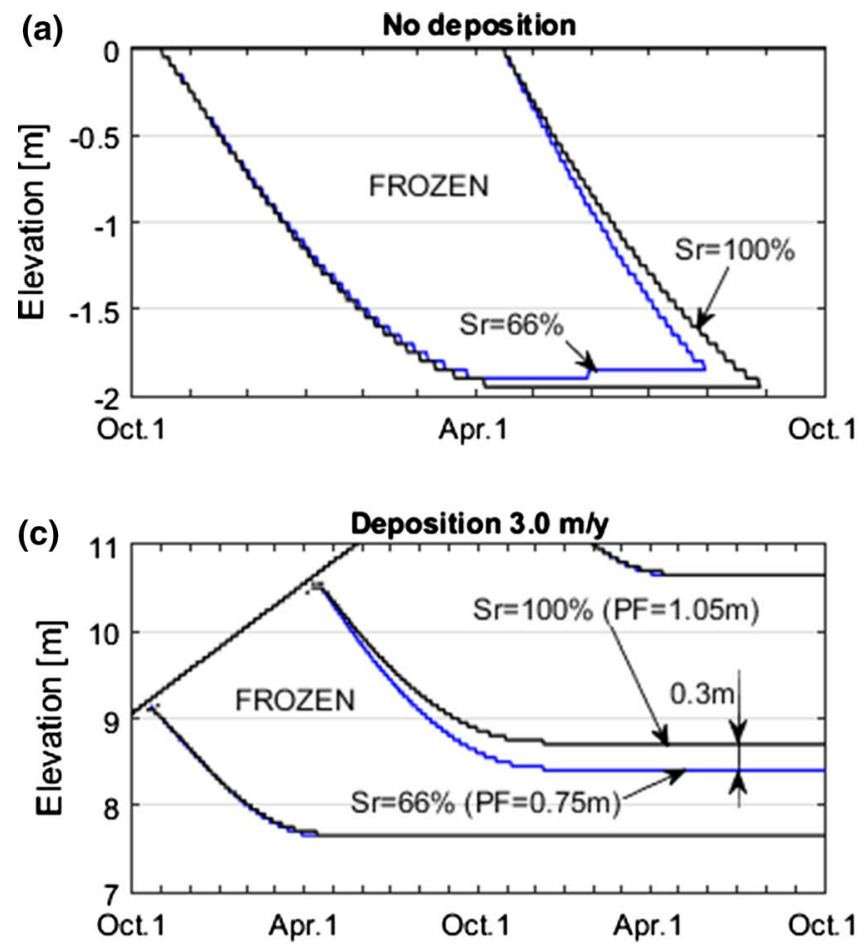

thaw depths. For the value $10{ }^{\circ} \mathrm{C}$, no effects were noticed neither on frost nor thaw depths. In Fig. 12 the effect of the increased value $\left(20^{\circ} \mathrm{C}\right)$ is presented. The maximum frost depth was decreased with $0.05 \mathrm{~m}$ (i.e., one element), but no influence was found on thaw depth.

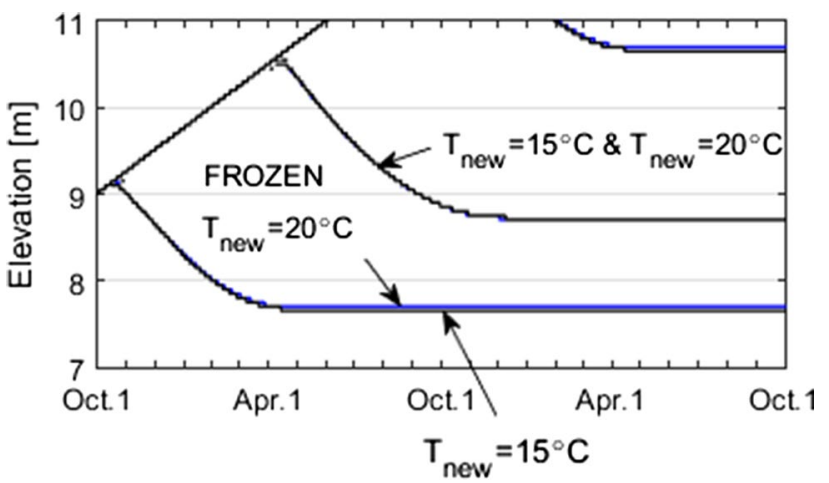

Fig. 12 Impact of temperature of new, added tailings. Black curves represent original value $\left(T_{\text {new }}=15^{\circ} \mathrm{C}\right)$ and blue curves the increased value $\left(T_{\text {new }}=20^{\circ} \mathrm{C}\right)$
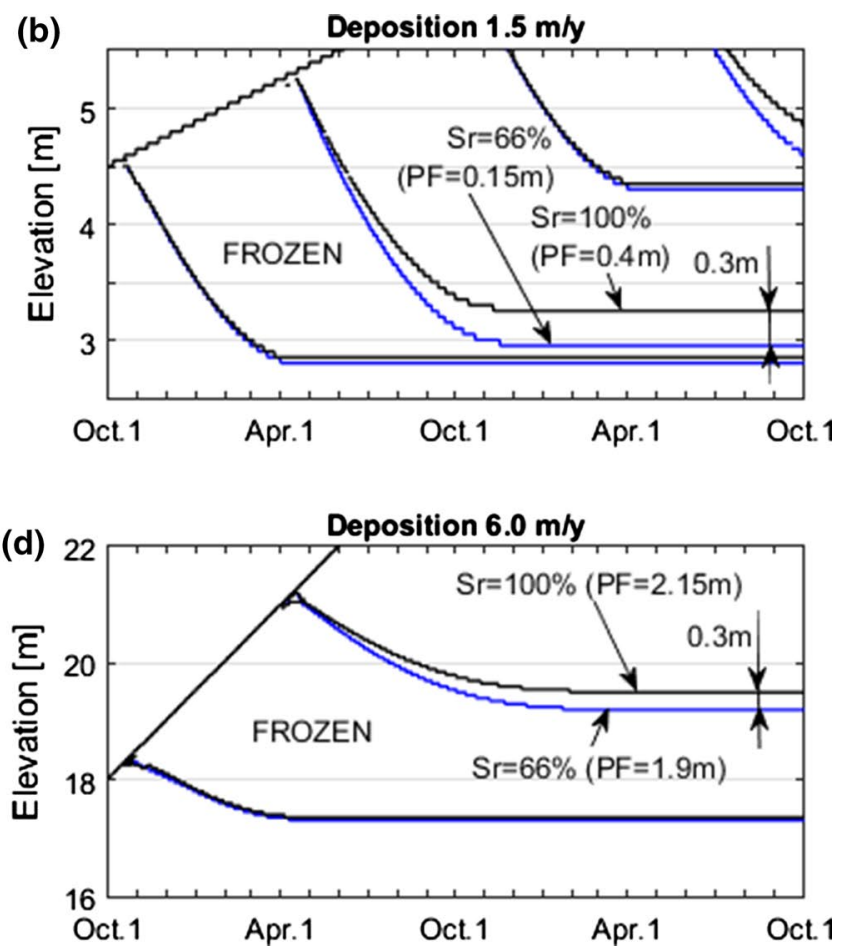

Fig. 11 Impact of degree of water saturation and deposition rates. Black curves represent original values $S_{\mathrm{r}}=100 \%$, and blue curves $S_{\mathrm{r}}=66 \%$. $P F$ Permafrost thickness 


\section{Discussion}

In this paper a model is described, simulating the thermal regime in tailings where site specific conditions are imported as input data, which has been subsequently used in the analysis. Such examples of input data are air temperatures, tailings deposition schedule, tailings properties, $n$-factors (ratio of air temperature and ground temperature) and temperature of the new tailings. Results from simulations can be assessed as either temperature profiles or moving freezing/thawing fronts with time, i.e., zero-isotherms.

Two cases were simulated and presented to illustrate the outcomes. Firstly, without tailings deposition and secondly, including tailings disposition with a constant height increase of $3 \mathrm{~m}$ per year. The two cases were simulated for a period of 5 years, with a similar air temperature acting at the tailings surface, as a boundary condition. The same tailings properties and corresponding thermal properties were used for the two cases. The simulations showed a clear difference in obtained thermal regime. The case with constant elevation of the tailings surface (no deposition) indicated thawing depths that reached the maximum frost depths and no frozen tailings are found after the summer. These results were expected since no natural permafrost exists in the area of study.

For the simulated case where the tailings surface was raised with time (tailings deposition $3 \mathrm{~m} / \mathrm{year}$ ), layers of tailings were found to remain frozen (see Fig. 9). The amount of heat that entered the tailings surface (in summer) was not sufficient to thaw all the frozen material due to the new material added on top. Man-made permafrost was generated due to the tailings deposition, and it remained frozen during the whole simulated period. The model's ability to capture multiple layers of permafrost when having deposition and concurrent freezing corresponds to results presented in Nixon and Holl (1998).

The sensitivity analysis indicated that the element size mainly affected the resolution of the zero-isotherms, see Fig. 10. Smaller elements give higher resolution (less stairway steps) than coarser elements. Since the required time step is automatically changed in the model, a decreased element size also generates a higher number of computations during the simulation. The choice of element size is therefore a matter of desirable resolution of the results with an adequate computation time.

For the temperature of the new tailings added on top, it was shown that the changes in temperature had a very low influence on the results. This finding is in agreement with results presented in Nazarova et al. (2015).

The sensitivity analysis also showed that the degree of water saturation has a bigger influence on the results than what is seen from altered element sizes or temperature of added tailings. Less water in the tailings, essentially increased the maximum thaw depths $(0.3 \mathrm{~m})$, and correspondingly decreased the thickness of the generated permafrost layers. The difference in the degree of saturation was resulting in similar permafrost decrease (i.e., $0.25-0.3 \mathrm{~m}$ ) irrespective of the deposition rate. But the deposition rate was the most influencing factor in the generation of permafrost. The deposition rates studied in the sensitivity analysis show that permafrost generation is clearly increased with increased deposition rate.

In this study only the heat balance was taken into account and in return hydro-mechanical aspects related to freezing and thawing were disregarded. Nonetheless, the tailings deposition plays a much larger role on the heat flow and corresponding permafrost generation than seen, based on the sensitivity study, from altered water contents. Considering the need for a model where tailings deposition is included in geothermal simulations, this motivates the model's simplicity. Tailings deposition, i.e., surface height increase with time, is included and simulations can aid in understanding the principle of generating man-made permafrost in tailings facilities. It should be noted that for other scenarios, e.g., in road design, hydro-mechanical aspects might be dominant and should be included in geothermal modelling. Such frost heave or thaw consolidation aspects are disregarded here.

The proposed model has been used in a separate case study where temperatures and frost/thaw depths in a tailings facility were simulated and compared to field measurements (Knutsson et al. 2018). Site specific air temperatures and tailings properties were used as input. Despite the model's simplicity, the thermal regime predicted with the model showed strong agreement with field conditions. The validation motivates further use of the model.

The presented model can be used to understand the effect of tailings deposition in cold regions. The thermal regime and corresponding development of the zero-isotherm are simulated and can be used to find a proper deposition schedule. This is a methodology that can aid in optimizing the tailings deposition, and be a complement to the methodology presented in Qiu and Sego (2006). Temperature data, given as input, can be assessed either from a weather station or from meteorological databases. Deposition data should be available from operational data from the mine, and tailings properties should be estimated based on geotechnical investigations. The data are then read as Excel spreadsheets into the MATLAB model.

The methodology presented can be used for applications other than tailings deposition. Excavations, filling and embankment construction in cold regions are examples of geotechnical structures where heat might be extracted and re-entered at different elevations. A consequence might therefore be man-made, built-in permafrost similar to what 
is shown in this study. The presented model can therefore be used to find the schedule when such construction work should be performed to avoid permafrost generation.

\section{Conclusions}

A one-dimensional geothermal model using the finite difference method is developed. The model simulates the temperature profile in tailings where the surface elevation is increased due to deposition. At the tailings surface the temperature is the boundary condition and changes with time. Air temperatures, tailings deposition, and tailings properties are given as input to the model and can therefore easily be adapted to specific facilities. The resolution of the results depends on the chosen element size, but where the computational effort is highly affected. The tailings properties play an important role on the thermal properties and correspondingly the results. The deposition rate is the most influencing factor in the generation of permafrost. The temperature of new tailings deposited on the surface has very low influence on the results. The model can be used for tailings facilities in cold regions, where thermal regimes are of interest for tailings management. Simulations can help setting up deposition schedules and thus prevent man-made permafrost layers.

Acknowledgements The financial support to this study was given by Luleå University of Technology (LTU) and is highly acknowledged. The authors would also like to express their thanks to Boliden Mineral $\mathrm{AB}, \mathrm{LKAB}$, and TCS AB. They have given encouraging support and valuable discussions on tailings management, and highlighted the need for guides on tailings deposition in cold regions.

Open Access This article is distributed under the terms of the Creative Commons Attribution 4.0 International License (http://creativeco mmons.org/licenses/by/4.0/), which permits unrestricted use, distribution, and reproduction in any medium, provided you give appropriate credit to the original author(s) and the source, provide a link to the Creative Commons license, and indicate if changes were made.

\section{References}

Andersland OB, Ladanyi B (2004) Frozen ground engineering, 2nd edn. Wiley, New Jersey

Barry-Macaulay D, Bouazza A, Wang B, Sing RM (2015) Evaluation of soil thermal conductivity models. Can Geotech $\mathrm{J}$ 52(11):1892-1900
Blight GE (2010) Geotechnical engineering for mine waste storage facilities. CRC Press, London

Caldwell JA, Revington A, McPhail G, Charlebois L (2014) Optimised seasonal deposition for successful management of treated mature fine tailings. In: Proceedings of the 17th international seminar on paste and thickened tailings, Vancouver

Farouki OT (1986) Thermal properties of soils, vol 11. Trans Tech Publications, Germany

Ho DM, Harrand ME, Leonards GA (1970) Transient temperature distribution in insulated pavements-predictions vs. observations. Can Geotech J 7(3):275-284

Johansen O (1975) Thermal conductivity of soils. Ph.D. thesis, University of Trondheim, Norway

Kincaid D, Cheney W (2002) Numerical analysis: mathematics of scientific computing, 3rd edn. The American Mathematical Society, Rhode Island

Knutsson R, Viklander P, Knutsson S (2016) Stability considerations for thickened tailings due to freezing and thawing. In: Proceedings of the 19th international seminar on paste and thickened tailings, Santiago

Knutsson R, Tuomela A, Rauhala A, Knutsson S, Laue J (2018) Geothermal study of a tailings deposit—-frost line modelling and comparison to field data. Int J Geo-Engineering (Under review)

Korshunov AA, Doroshenko SP, Nevzorov AL (2016) The impact of freezing-thawing process on slope stability of earth structure in cold climate. Procedia Eng 143:682-688

Ma W, Zhang L, Yang C (2015) Discussion of the applicability of the generalized Clausius-Clapeyron equation and the frozen fringe process. Earth Sci Rev 142:47-59

MathWorks Inc. (2016) MATLAB 2016. www.mathworks.com. Accessed 05 Sept 2017

McRoberts EC, Morgenstern NR (1974) The stability of thawing slopes. Can Geotech J 11(4):447-469

Morgenstern NR, Nixon JF (1971) One-dimensional consolidation of thawing soils. Can Geotech J 8(4):558-578

Nazarova LA, Nazarov LA, Dzhamanbaev MD, Chynybaev MK (2015) Evolution of thermohydrodynamic fields at tailings dam at Kumtor Mine (Kyrgyz Republic). J Min Sci 51(1):17-22

Nixon JF, Holl N (1998) Geothermal modeling of soil or mine tailings with concurrent freezing and deposition. Can Geotech J 35(2):234-250

Peppin SSL, Style RW (2013) The physics of frost heave and ice-lens growth. Vadose Zone J 12(1):1-12

Qiu Y, Sego DC (2006) Optimum deposition for sub-aerial tailings disposal: concept and theories. Int J Min Reclam Environ 20(4):272-285

Vick SG (1990) Planning, design and analysis of tailings dams. BiTech Publishers, Vancouver

Wang W, Wang L, Yu F, Wang Q (2014) Thaw consolidation behaviors of embankments in permafrost regions with periodical temperature boundaries. KSCE J Civ Eng 20(4):1250-1258

Wen Z, Ma W, Feng W, Deng Y, Wang D, Fan Z, Zhou C (2012) Experimental study on unfrozen water content and soil matric potential of Qinghai-Tibetan silty clay. Environ Earth Sci 66:1467-1476 